\title{
Seizures and Tumor Progression in Glioma Patients with Uncontrollable Epilepsy Treated with Perampanel
}

\author{
SHUICHI IZUMOTO ${ }^{1}$, MASAHARU MIYAUCHI ${ }^{1}$, TAKAYUKI TASAKI ${ }^{1}$, TAKESHI OKUDA ${ }^{1}$, \\ NOBUHIRO NAKAGAWA ${ }^{1}$, NAOKI NAKANO ${ }^{1}$, AMAMI KATO ${ }^{1}$ and MITSUGU FUJITA ${ }^{2}$ \\ ${ }^{1}$ Department of Neurosurgery, Kindai University Faculty of Medicine, Osaka-Sayama, Japan; \\ ${ }^{2}$ Department of Microbiology, Kindai University Faculty of Medicine, Osaka-Sayama, Japan
}

\begin{abstract}
Background/Aim: Excessive extracellular glutamate activates AMPA-type glutamate receptors (AMPA receptors) and induces seizures. Antagonistic activation of AMPA receptors inhibits epilepsy and glioma growth in in vitro and in vivo studies. This study was conducted to evaluate the clinical impacts of perampanel (PER), a novel AMPA receptor antagonist, on seizures and tumor progression in glioma patients with uncontrollable epilepsy. Patients and Methods: Twelve glioma patients with uncontrollable epilepsy were treated with PER. Seizure response, PER concentration, and tumor volume were assessed. Results: Obvious seizure control was observed in 10 analyzed patients $(100 \%)$ and 6 patients $(60 \%)$ became seizure-free. Median plasma concentrations of PER were 296 $\mathrm{ng} / \mathrm{ml}$ in those with $4 \mathrm{mg} /$ day PER treatment and $518 \mathrm{ng} / \mathrm{ml}$ in those with $8 \mathrm{mg} /$ day PER treatment. High-intensity lesions in fluid-attenuated inversion recovery of magnetic resonance imaging (MRI) were volumetrically assessed to analyze tumor size. Volume reduction was detected within 6 months in correlation with increased plasma levels of PER. Conclusion: PER treatment was effective in uncontrollable epilepsy with gliomas. MRI images showed the inhibition of tumor growth.
\end{abstract}

The central nervous system utilizes glutamate as a neurotransmitter. As excessive extracellular glutamate could elicit excitotoxicity, various mechanisms appear to strictly control extracellular concentrations of glutamate. Glioma cells release glutamate via glutamate/cystine antiporter exchange system

Correspondence to: Shuichi Izumoto, MD, Ph.D., Associate Professor, Department of Neurosurgery, Kindai University Faculty of Medicine, 377-2 Ohno-Higashi, Osaka-Sayama, Osaka 589-8511, Japan. Tel: +81 723660221, Fax: +81 723656975, e-mail: sizumoto@med.kindai.ac.jp; Mitsugu Fujita, MD, Ph.D., Associate Professor, Department of Microbiology, Kindai University Faculty of Medicine, 377-2 OhnoHigashi, Osaka-Sayama, Osaka 589-8511, Japan. Tel: +81 723660206, Fax: +81823660206, e-mail: mfujita47@gmail.com

Key Words: Glioma, epilepsy, perampanel, AMPA receptor, antiepileptic drug.
(System Xc). The released glutamate further promotes survival and proliferation of glioma cells in an autocrine fashion (1). The glutamate released in the intercellular space also activates both synaptic and extra-synaptic AMPA-type glutamate receptor (AMPA receptor) and induces seizures $(2,3)$. It could also cause degeneration of normal brain cells and peritumoral edema $(4,5)$. During glioma treatment, approximately $50-90 \%$ of patients exhibit epilepsy, and $15-40 \%$ of patients acquire pharmaco-resistant epilepsy (6-8). Thus, there may be a close link between seizures and glioma progression. In this regard, recent data have shown that drug-resistant epilepsy (DRE) frequently occurs in glioma patients probably by mechanisms involving AMPA receptor activation that leads to seizure activity and glioma cell growth $(9,10)$. Glutamate receptor subunits expressed on tumor cells are closely linked to biochemical pathways that regulate malignant phenotypes (11, 12). The inhibition of AMPA receptors could ameliorate epilepsy and glioma growth $(1,5,13)$. Based on these findings, a retrospective chart review of glioma patients with uncontrollable epilepsy treated with perampanel (PER), a novel AMPA receptor antagonist, was conducted.

\section{Patients and Methods}

Twelve patients with uncontrollable epilepsy despite administration of other anti-epileptic drugs (AED) were treated with PER consecutively at the Department of Neurosurgery, Kindai Hospital. Age over 18 years, glial tumor type, recurrent seizure activity at the time of initiating PER, and usage of at least one AEDs prior to the PER treatment were evaluated as patient characteristics. All patients with malignant glioma had been treated with Stupp regimen prior to the PER treatment. The PER treatment started at $2 \mathrm{mg}$ per day before bedtime and was up-titrated by $2 \mathrm{mg}$ increment with more than a week interval. If seizures stopped for a month, the same dose was maintained. Dose reduction of concurrent AEDs was considered when the patients stayed seizure-free for 6 weeks or more. The plasma concentration of PER $(\mathrm{ng} / \mathrm{ml})$ at the maintenance dose was measured by LSI Medience Corporation (14). The 50\% reduction of seizure frequency or the achievement of seizure freedom was considered therapeutically effective. High-intensity lesions in fluid-attenuated inversion recovery (FLAIR) of magnetic resonance imaging (MRI) 
were volumetrically assessed to analyze the tumor volume and peritumoral edema for 6 months. Volumetry was conducted after image fusion via iPlan 3.0 (BrainLAB AG, Munich, Germany) based on manual sequencing of FLAIR images according to the method previously described $(15,16)$ and the volume changes within 6 months were evaluated. The correlation between the volume changes and the plasma concentrations of PER was also evaluated.

\section{Results}

Twelve patients ( 8 males and 4 females, median age of 59 years) were treated with PER. Patient characteristics including types of tumor and seizure are shown in Table I. Two patients were grade 2 glioma (1 diffuse astrocytoma and 1 oligoastrocytoma), 8 patients were grade 3 glioma (3 anaplastic astrocytoma and 5 anaplastic oligodendroglioma), and 2 patients were grade 4 glioma (glioblastoma multiforme / GBM). Concomitant drugs are described in Table II. During the PER administration, temozolomide (TMZ) was used in 6 patients, and bevacizumab was used in 3 patients.

Patients with one or two AEDs were treated with PER. Nine patients were treated with $4 \mathrm{mg}$ of PER and 3 patients were treated with $8 \mathrm{mg}$ as maintenance doses. A patient (Case 2) discontinued PER because of intolerable dizziness at a dose of $4 \mathrm{mg}$. Another patient (Case 10) died due to intratumor hemorrhage caused by head injury. These two patients were excluded due to lack of the therapeutic efficacy. PER was down-titrated from 6 to $4 \mathrm{mg}$ in Case 3 because of sluggish speech and dizziness after alcohol intake. After down-titration to $4 \mathrm{mg}$, these symptoms disappeared but the seizure was well controlled. Ten patients including Case 3 continued the PER treatment and their data were included in the efficacy analysis. Seizure aggravation was not observed in response to PER.

All 10 patients achieved more than $50 \%$ seizure reduction. Among them, 6 patients became seizure-free. Seven patients were maintained with $4 \mathrm{mg} /$ day of PER and 3 patients were maintained with $8 \mathrm{mg} /$ day of PER. Doses of concomitant AEDs were reduced in 4 patients because they were seizurefree for 6 weeks or more.

The median plasma concentration of PER was $296 \mathrm{ng} / \mathrm{ml}$ in glioma patients with $4 \mathrm{mg} /$ day PER, and $518 \mathrm{ng} / \mathrm{ml}$ in glioma patients with $8 \mathrm{mg} /$ day PER. However, the plasma concentration of PER in the patients with $4 \mathrm{mg} /$ day PER had a wide range (range $=110-906 \mathrm{ng} / \mathrm{ml}$; Table II and Figure 1). Doses of other AEDs were all in the effective range (data not shown). Tumor volume and peritumoral edema within 6 months were volumetrically analyzed by MRI-FLAIR images, and the volume changes were evaluated. The tumor volume decreased in eight of 9 patients during 6 months by FLAIR image (Figure 2) and increased in one (Case 9) of 9 patients. The other one patient was excluded from analysis because of no detectable FLAIR-high lesion on MRI. Figure 2 shows the 2D-MRI images of representative 5 responding patients before and 6 months after the initiation of the PER treatment.
Table I. Patient characteristics.

\begin{tabular}{lc}
\hline No. of patients & 12 \\
M/F & $8 / 4$ \\
Median age (range) & $59(31-84)$ \\
Type of tumor & \\
Low-grade astro- or oligoastrocytoma & 2 \\
Anaplastic astro- or oligodendroglioma & 8 \\
Glioblastoma & 2 \\
Seizure as initial presenting sign of tumor & 9 \\
Type of epilepsy & \\
Simple partial seizures & 8 \\
Secondary generalized seizures & 4 \\
\hline
\end{tabular}

The volume changes of the FLAIR images within 6 months were compared with the plasma concentrations of PER. Regression analysis indicated that the volume reduction was correlated with the plasma concentration of PER $\left(\mathrm{R}^{2}=0.6909\right.$; Figure 3). Higher plasma PER levels were found in 3 patients that showed high reduction ratio.

\section{Discussion}

PER was administered to a series of patients with uncontrollable epilepsy related to both low- and high-grade gliomas. Among them, 10 patients achieved more than $50 \%$ seizure reduction and 6 patients became seizure-free. Vecht et al. (17) have reported that $50 \%$ of their glioma patients achieved seizure freedom and that $25 \%$ experienced more than $50 \%$ seizure reduction, which is consistent with our results. In a randomized phase 3 study in which patients with partial-onset DREs were treated with PER, $36 \%$ of the patients achieved $50 \%$ seizure reduction at a dose of $8 \mathrm{mg} /$ day (18). In real-world clinical experience, PER promoted more than 50 seizure reduction in $48.6 \%$ of patients, and $14.3 \%$ became seizure-free (19). In addition, PER appears to control seizures in glioma patients more effectively than those without glioma $(8,20,21)$. Smaller efficacy size in DRE patients without glioma might be attributable to the inclusion of highly drug-resistant population.

Seizure occurrence in glioma patients is related to high peritumoral glutamate concentrations. The excessive glutamate concentrations in peritumor lesions might be attributable to its release from glioma cells through the System Xc (1, 3, 21). This glutamate release could also occur in extra-synaptic space. Ectopically-released glutamate might remain in situ due to the lack of sufficient system for glutamate clearance. Therefore, the direct antagonistic activity of PER against peritumoral glutamate appears to promote the prominent antiepileptic effects in this population. Our results indicate that all 5 patients with uncontrollable secondarily generalized seizure achieved more than $50 \%$ reduction in seizure frequency. Seven of 9 patients with $4 \mathrm{mg}$ PER also achieved more than $50 \%$ 
Table II. Summary of results.

\begin{tabular}{|c|c|c|c|c|c|c|c|c|c|c|c|c|c|c|c|}
\hline Case & Age & Gender & $\begin{array}{l}\text { Glioma } \\
\text { type }\end{array}$ & $\begin{array}{c}\text { Initial } \\
\text { symptom }\end{array}$ & $\begin{array}{l}\text { Seizure } \\
\text { type }\end{array}$ & AED & $\begin{array}{l}\text { Seizure } \\
\text { after } \\
\text { PER }\end{array}$ & $\begin{array}{l}\text { Seizure } \\
50 \% \\
\text { response }\end{array}$ & $\begin{array}{l}\text { Seizure } \\
\text { free }\end{array}$ & TMZ & $\mathrm{Bev}$ & $\begin{array}{l}\text { Post } \\
\text { RT } \\
\text { (M) }\end{array}$ & $\begin{array}{c}\text { Change of } \\
\text { tumor size }(\%) \\
\text { (FLAIR) }\end{array}$ & $\begin{array}{c}\text { Plasma } \\
\text { PER-4 mg } \\
(\mathrm{ng} / \mathrm{ml})\end{array}$ & $\begin{array}{l}\text { Plasma } \\
\text { PER-8 mg } \\
(\mathrm{ng} / \mathrm{ml})\end{array}$ \\
\hline 1 & 31 & M & As & SGS & SGS & LEV & SPS & 0 & & & & 4 & 92.6 & & 506 \\
\hline $2^{\#}$ & 75 & M & OA & SPS & SPS & LEV & \# & $\#$ & $\#$ & + & + & 0 & NT & NT & \\
\hline 3 & 32 & $\mathrm{~F}$ & AA & headache & SPS & VPA & - & & 0 & & & 24 & 82.5 & 612 & \\
\hline 4 & 65 & M & AA & SGS & SPS & LEV & - & & 0 & & + & 15 & 25.2 & 906 & \\
\hline 5 & 70 & M & AA & SPS & SGS & LEV+VPA & - & & 0 & + & & 20 & 72.6 & 218 & \\
\hline 6 & 42 & M & $\mathrm{AO}$ & SGS & SGS & LEV & - & & 0 & + & & 22 & 63.0 & & 518 \\
\hline 7 & 47 & M & $\mathrm{AO}$ & SGS & SGS & LEV & SPS & 0 & & + & & 14 & 63.4 & & 528 \\
\hline 8 & 74 & $\mathrm{~F}$ & $\mathrm{AO}$ & SGS & SPS & LEV & - & & 0 & + & & 6 & 16.6 & 871 & \\
\hline 9 & 37 & $\mathrm{~F}$ & $\mathrm{AO}$ & SGS & SPS & $\mathrm{PHE}+\mathrm{CLO}$ & SPS & 0 & & & & 141 & 105.3 & 110 & \\
\hline $10^{*}$ & 53 & $\mathrm{~F}$ & $\mathrm{AO}$ & headache & SPS & VPA & $*$ & $*$ & $*$ & & & 118 & NT & NT & \\
\hline 11 & 83 & M & GB & $\mathrm{h}$-paresis & SGS & VPA & SPS & 0 & & & & 9 & NT & 291 & \\
\hline 12 & 84 & M & GB & SPS & SPS & LEV & - & & 0 & + & + & 6 & 84.3 & 296 & \\
\hline
\end{tabular}

\#Dropped out; *discontinued; As: diffuse astrocytoma; OA: oligoastrocytoma; AA: anaplastic astrocytoma; AO: anaplastic oligodendroglioma; GB: glioblastoma; SGS: secondary generalized seizure; SPS: simple partial seizure; AEC: anti-epileptic drug; TMZ: temozolomide; Bev: bevacizumab; CLO: clobazam; LEV: levetiracetam; VPA: valproic acid; PHE: phenytoin; RT: radiation therapy.

reduction of seizure frequency, supporting the gliomaspecific etiology of seizures.

Only one patient was excluded from the PER treatment because of its side-effects. Another patient also showed side effects at $6 \mathrm{mg} /$ day of PER but recovered after dose reduction to $4 \mathrm{mg}$. Over the 6-month evaluation period, a dropout from the PER treatment was 1 out of 12 patients $(8.3 \%)$, which indicates that the tolerability of PER was acceptable.

All patients were treated with at least one AED prior to the PER treatment, and the median PER dose was $4 \mathrm{mg}$, which is the minimal efficacious dose of PER in DRE. Earlier use and lower doses might reduce the incidence and severity of the side effects and increase retention.

Talampanel was formerly developed as a noncompetitive AMPA antagonist prior to PER but not marketed as an AED because of its short terminal half-life and association with several adverse events including ataxia and dizziness. Nevertheless, it demonstrated therapeutic efficacy in patients with partial-onset DREs (22). For glioma treatment, talampanel along with radiotherapy and TMZ has exhibited survival benefit in patients with newly diagnosed GBM (23) but had no significant activity as a single agent in recurrent malignant gliomas (24). Thereafter, PER has been developed as a novel non-competitive AMPA-receptor antagonist and approved as adjunctive therapy for seizure treatment. PER has excellent brain penetration, a long half-life and drug concentration profile compared with talampanel $(25,26)$.

We measured the plasma level of PER at steady state when the dose of PER was maintained for at least two weeks. The median plasma concentration of PER was $296 \mathrm{ng} / \mathrm{ml}$ in glioma patients with $4 \mathrm{mg} /$ day PER treatment and $518 \mathrm{ng} / \mathrm{ml}$ in glioma

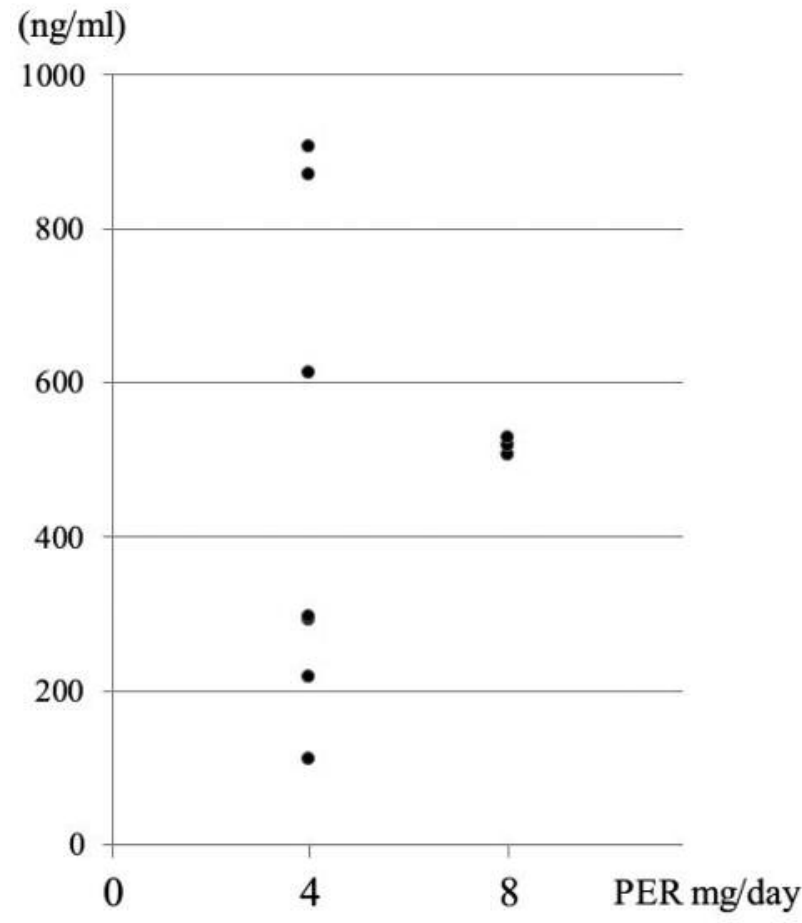

Figure 1. Plasma concentrations of PER. Administration dose of PER and plasma concentration of PER in each patient are plotted.

patients with $8 \mathrm{mg} / \mathrm{day}$ PER treatment. These values are similar to those in previous Japanese studies $(27,28)$. Our data indicate that the plasma concentration of PER in patients with $4 \mathrm{mg} /$ day PER had a wide range (110-906 ng/ml). Other AED doses were 

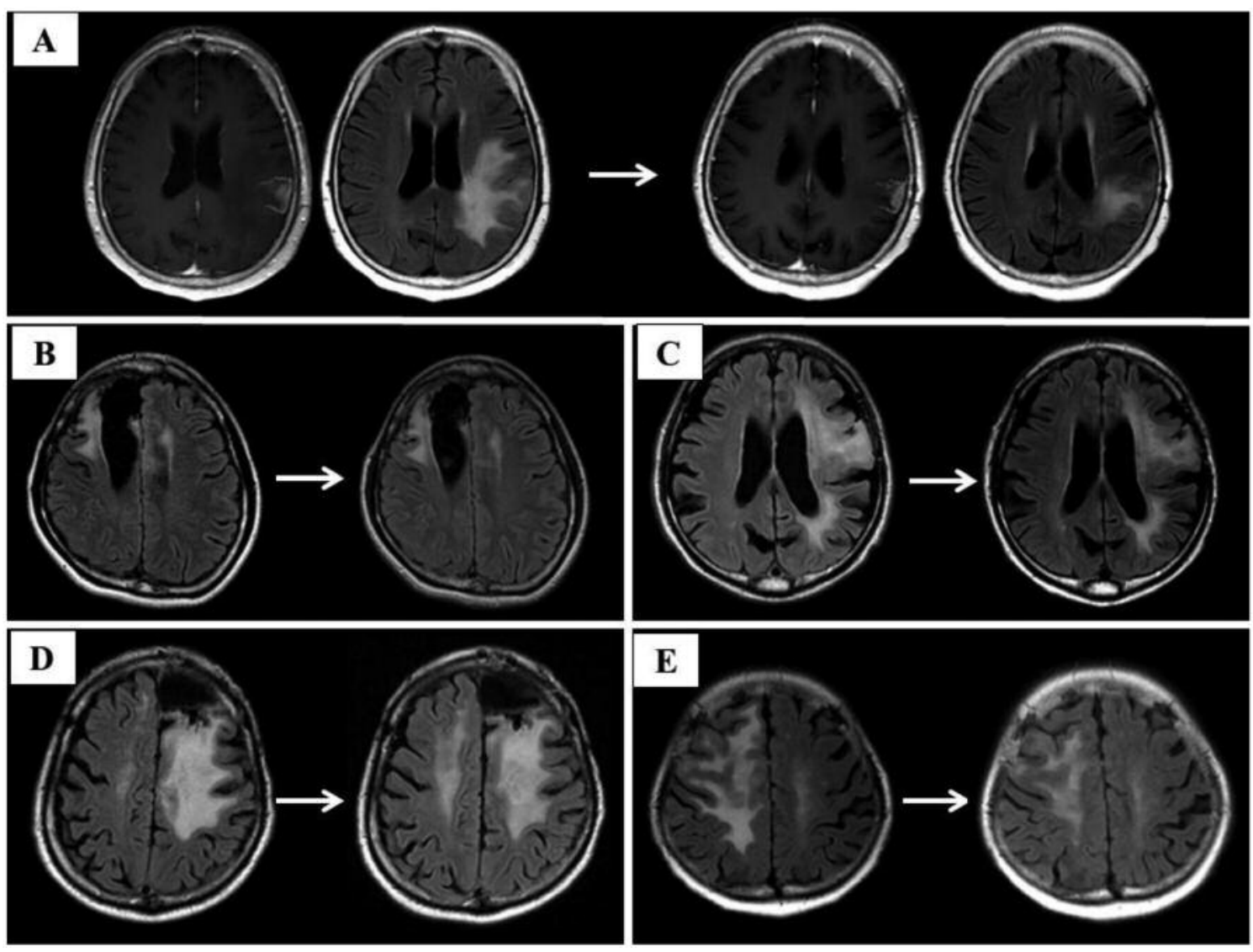

Figure 2. Radiographical responses to PER. Five cases of MRI-FLAIR images before and 6 months after the treatment of PER. High-intensity lesions decreased in size. A: Case 8 including Gd-enhanced T1WI, B: Case 3, C: Case 4, D: Case 5, E: Case 12.

all within effective range (data not shown). One patient (Case 9) treated with $4 \mathrm{mg} /$ day PER and $225 \mathrm{mg}$ /day phenytoin had low plasma PER concentrations. It is probably because phenytoin is an enzyme (CYP3A4)-inducing antiepileptic drug that enhances the clearance of PER (29).

A large inter-individual difference of PER plasma concentration was found in our patients. Known drugs or foods that inhibit CYP3A metabolites were not administered to patients with higher plasma concentrations of PER. As the interindividual and ethnic differences are known for the expression levels of CYP3A, these factors might be responsible for the large variation of plasma concentration of PER in this study (30).

Tumor growth and peritumoral edema within 6 months were analyzed by the volume changes of high-intensity lesion of MRI-FLAIR images. A strong correlation has been revealed between $2 \mathrm{D}$ and $3 \mathrm{D}$ volumetric measurements (31), and $3 \mathrm{D}$ images are known to be more informative. Therefore, we used 3D measurements in this study. Shrinkage of the high-intensity lesion on MRI-FLAIR was detected in 8 of 10 patients treated with PER. The volume reduction was well correlated with the plasma concentration of PER.
The results of this study suggest the inhibitory effects of PER on tumor progression and/or peritumoral brain edema. Of note, all the patients with extremely high plasma PER levels exhibited glioma growth inhibition. One explanation for the close link between seizures inhibition and glioma growth inhibition is elevated extracellular glutamate levels in the peri-glial and peri-neuronal spaces that may cause the excessive activities of AMPA-receptors in both conditions (1, 13). In vitro and in vivo studies have shown that AMPA receptor inhibition arrests glioma growth and invasion $(9,32$, 33). In a clinical case report from Germany, a PER-treated GBM patient without isocitrate dehydrogenase $(I D H)$ gene mutation and $O^{6}$-methylguanine DNA methyltransferase (MGMT) gene expression survived for a year longer (34). PER may provide the therapeutic opportunities for both seizure control and anti-tumor effects as a non-competitive AMPA inhibitor (23), although the cytotoxic effect of PER against glioma cells may not be cytocidal but cytostatic. In this study, 6 patients had TMZ and 3 patients had bevacizumab along with PER; these chemotherapeutic agents may have influenced glioma growth inhibition. However, 


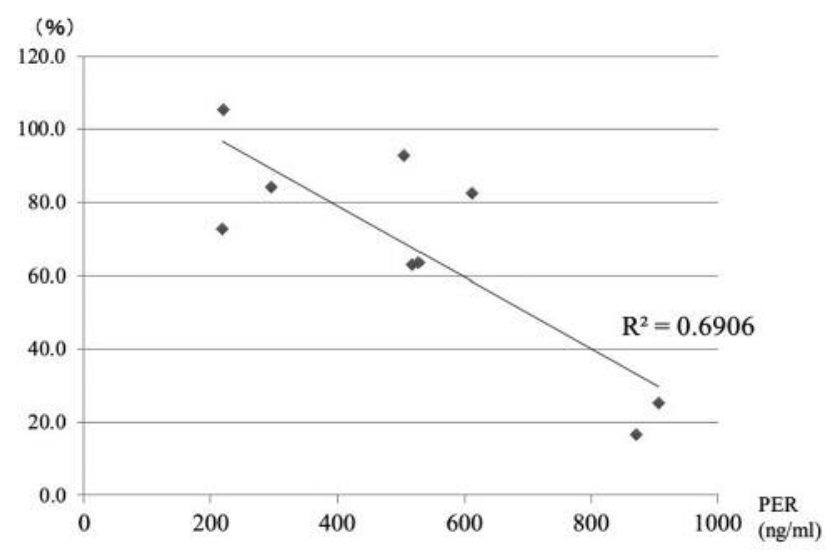

Figure 3. Correlation between MRI-based volume changes and plasma concentrations of PER. Tumor growth and peritumoral edema for 6 months were analyzed by $3 D-M R I$ with volumetric measurements of high-intensity lesions of MRI-FLAIR images (by Brain Labo software iPlan Cranial 3.0), and the volume reduction was compared to the plasma concentration of PER. The volume reduction ratios (\%) of FLAIR images $(=$ MRI 6 months after the initiation of PER/MRI immediately before the seizure that required the administration of PER were on the Y-axis, and the plasma concentrations of PER were on the $X$-axis. The volume reduction (\%) correlated with the plasma concentration of PER $\left(R^{2}=0.6909\right)$ by regression analysis.

TMZ was maintained at least 3 months prior to the PER treatment and the MR images did not change during this period. Izquierdo et al. (35) have reported that mean tumor diameter of low-grade glioma progressively decreased in most patients $(94.4 \%)$ with a median slope of $-5.7 \mathrm{~mm} /$ year (range $=-14.84$ to $-0.85 \mathrm{~mm} /$ year) and for a median duration of 23 months after TMZ treatment. In GBM, median time to progression according to the Response Assessment in NeuroOncology (RANO) criteria was 6.4 months (36). These results suggested that our patients had refractory tumors against TMZ. Regarding bevacizumab, Case 12 also showed a decrease in gadolinium ( $\mathrm{Gd}$ )-enhanced lesions but not in the FLAIR-high lesions during the bevacizumab treatment. However, the FLAIR-high lesion decreased after the administration of PER. In Case 8 without bevacizumab, Gdenhanced lesions slightly decreased, and FLAIR-high lesion obviously decreased in response to the PER treatment. Corticosteroids ( $1 \mathrm{mg}$ of betamethasone) were used in 3 patients, but their dose was unchanged during the 6 months. These results suggested that bevacizumab had minimal effect on the results in this study and that the underlying mechanism for the reduction of tumor volume in response to the PER might be an antitumor effect rather than a mere reduction of peritumoral edema.

In conclusion, more than $50 \%$ seizure reduction and seizure-freedom were observed in evaluated patients with uncontrollable epilepsy treated with PER. PER treatment for tumor-related uncontrollable epilepsy was more effective than for those with tumor-irrelevant uncontrollable epilepsy. Furthermore, MRI images of glioma patients showed tumor growth inhibition and/or peritumoral brain edema reduction in correlation with the plasma concentrations of PER. These favorable results warrant a randomized study of PER to determine seizure and tumor responses in uncontrollable epilepsy with glioma.

\section{Conflicts of Interest}

The Authors declare that they have no conflict of interest regarding this study.

\section{Acknowledgements}

This work was supported by the following JSPS KAKENHI grants: 17K10881 (S.I.) and 16K10348 (M.F.). The Authors thank Edanz Group (www.edanzediting.com/ac) for editing a draft of this manuscript.

\section{References}

1 de Groot $\mathrm{J}$ and Sontheimer H: Glutamate and the biology of gliomas. Glia 59: 1181-1189, 2011.

2 Huberfeld G and Vecht CJ: Seizures and gliomas - towards a single therapeutic approach. Nat Rev Neurol 12: 204-216, 2016.

3 Neal A, Yuen T, Bjorksten AR, Kwan P, O'Brien TJ and Morokoff A: Peritumoural glutamate correlates with postoperative seizures in supratentorial gliomas. J Neurooncol 129: 259-267, 2016.

4 Savaskan NE, Fan Z, Broggini T, Buchfelder M and Eyüpoglu IY: Neurodegeneration and the Brain Tumor Microenvironment. Curr Neuropharmacol 13: 258-265, 2015.

5 Westergren I and Johansson BB: Blockade of AMPA receptors reduces brain edema following opening of the blood-brain barrier. J Cereb Blood Flow Metab 13: 603-608, 1993.

6 van Breemen MS, Wilms EB and Vecht CJ: Epilepsy in patients with brain tumours: epidemiology, mechanisms, and management. Lancet Neurol 6: 421-430, 2007.

7 Pallud J, Audureau E, Blonski M, Sanai N, Bauchet L, Fontaine D, Mandonnet E, Dezamis E, Psimaras D, Guyotat J, Peruzzi P, Page P, Gal B, Párraga E, Baron MH, Vlaicu M, Guillevin R, Devaux B, Duffau H, Taillandier L, Capelle L and Huberfeld G: Epileptic seizures in diffuse low-grade gliomas in adults. Brain 137: 449-462, 2014.

8 Armstrong TS, Grant R, Gilbert MR, Lee JW and Norden AD: Epilepsy in glioma patients: mechanisms, management, and impact of anticonvulsant therapy. Neuro Oncol 18: 779-789, 2016.

9 Ishiuchi S, Yoshida Y, Sugawara K, Aihara M, Ohtani T, Watanabe T, Saito N, Tsuzuki K, Okado H, Miwa A, Nakazato $\mathrm{Y}$ and Ozawa S: Ca2+-permeable AMPA receptors regulate growth of human glioblastoma via Akt activation. J Neurosci 27: 7987-8001, 2007.

10 Lee SG, Su ZZ, Emdad L, Sarkar D, Franke TF and Fisher PB: Astrocyte elevated gene-1 activates cell survival pathways through PI3K-Akt signaling. Oncogene 27: 1114-1121, 2008. 
11 Luksch H, Uckermann O, Stepulak A, Hendruschk S, Marzahn J, Bastian S, Staufner C, Temme A and Ikonomidou C: Silencing of selected glutamate receptor subunits modulates cancer growth. Anticancer Res 31: 3181-3192, 2011.

12 Stepulak A, Luksch H, Uckermann O, Sifringer M, Rzeski W, Polberg K, Kupisz K, Klatka J, Kielbus M, Grabarska A, Marzahn J, Turski L and Ikonomidou C: Glutamate receptors in laryngeal cancer cells. Anticancer Res 31: 565-573, 2011.

13 Robel S and Sontheimer H: Glia as drivers of abnormal neuronal activity. Nat Neurosci 19: 28-33, 2016.

14 Mano Y, Takenaka O and Kusano K: High-performance liquid chromatography-tandem mass spectrometry method for the determination of perampanel, a novel $\alpha$-amino-3-hydroxy-5methyl-4-isoxazolepropionic acid receptor antagonist in human plasma. J Pharm Biomed Anal 107: 56-62, 2015.

15 Pala A, Brand C, Kapapa T, Hlavac M, König R, Schmitz B, Wirtz $\mathrm{CR}$ and Coburger $\mathrm{J}$ : The value of intraoperative and early postoperative magnetic resonance imaging in low-grade glioma surgery: A Retrospective Study. World Neurosurg 93: 191-197, 2016.

16 Marinelli JP, Van Gompel JJ, Link MJ, Moore EJ, Price DL, Lees KA, Kaczor MW and Janus JR: Volumetric analysis of olfactory neuroblastoma skull base laterality and implications on neck disease. Laryngoscope 128: 864-870, 2018.

17 Vecht C, Duran-Peña A, Houillier C, Durand T, Capelle L and Huberfeld G: Seizure response to perampanel in drug-resistant epilepsy with gliomas: early observations. J Neurooncol 133: 603-607, 2017.

18 Krauss GL, Serratosa JM, Villanueva V, Endziniene M, Hong Z, French J, Yang H, Squillacote D, Edwards HB, Zhu J and Laurenza A: Randomized phase III study 306: adjunctive perampanel for refractory partial-onset seizures. Neurology 78 : 1408-1415, 2012.

19 Kurth C, Kockelmann E and Steinhoff BJ: Clinical outcomes of perampanel vs. lacosamide in cohorts of consecutive patients with severely refractory epilepsies - A monocentric retrospective analysis of systematically collected data from the German Kork Epilepsy Center. Seizure 45: 47-51, 2017.

20 French JA, Krauss GL, Biton V, Squillacote D, Yang H, Laurenza A, Kumar D and Rogawski MA: Adjunctive perampanel for refractory partial-onset seizures: randomized phase III study 304. Neurology 79: 589-596, 2012.

21 French JA, Krauss GL, Steinhoff BJ, Squillacote D, Yang H, Kumar $\mathrm{D}$ and Laurenza A: Evaluation of adjunctive perampanel in patients with refractory partial-onset seizures: results of randomized global phase III study 305. Epilepsia 54: 117-125, 2013.

22 Chappell AS, Sander JW, Brodie MJ, Chadwick D, Lledo A, Zhang D, Bjerke J, Kiesler GM and Arroyo S: A crossover, addon trial of talampanel in patients with refractory partial seizures. Neurology 58: 1680-1682, 2002.

23 Grossman SA, Ye X, Chamberlain M, Mikkelsen T, Batchelor T, Desideri S, Piantadosi S, Fisher J and Fine HA: Talampanel with standard radiation and temozolomide in patients with newly diagnosed glioblastoma: a multicenter phase II trial. J Clin Oncol 27: 4155-4161, 2009.

24 Iwamoto FM, Kreisl TN, Kim L, Duic JP, Butman JA, Albert PS and Fine HA: Phase 2 trial of talampanel, a glutamate receptor inhibitor, for adults with recurrent malignant gliomas. Cancer 116: 1776-1782, 2010.

25 Hanada T, Hashizume Y, Tokuhara N, Takenaka O, Kohmura N, Ogasawara A, Hatakeyama S, Ohgoh M, Ueno M and Nishizawa
Y: Perampanel: a novel, orally active, noncompetitive AMPAreceptor antagonist that reduces seizure activity in rodent models of epilepsy. Epilepsia 52: 1331-1340, 2011.

26 Hibi S, Ueno K, Nagato S, Kawano K, Ito K, Norimine Y, Takenaka O, Hanada T and Yonaga M: Discovery of 2-(2-oxo1-phenyl-5-pyridin-2-yl-1,2-dihydropyridin-3-yl)benzonitrile (perampanel): a novel, noncompetitive $\alpha$-amino-3-hydroxy-5methyl-4-isoxazolepropanoic acid (AMPA) receptor antagonist. J Med Chem 55: 10584-10600, 2012.

27 Yamamoto Y, Usui N, Nishida T, Takahashi Y, Imai K, Kagawa Y and Inoue Y: Therapeutic Drug Monitoring for Perampanel in Japanese Epilepsy Patients: Influence of Concomitant Antiepileptic Drugs. Ther Drug Monit 39: 446-449, 2017.

28 Gidal BE, Ferry J, Majid O and Hussein Z: Concentration-effect relationships with perampanel in patients with pharmacoresistant partial-onset seizures. Epilepsia 54: 1490-1497, 2013.

29 Gidal BE, Laurenza A, Hussein Z, Yang H, Fain R, Edelstein J, Kumar D and Ferry J: Perampanel efficacy and tolerability with enzyme-inducing AEDs in patients with epilepsy. Neurology 84 : 1972-1980, 2015.

30 Yamaori S, Yamazaki H, Iwano S, Kiyotani K, Matsumura K, Saito T, Parkinson A, Nakagawa $\mathrm{K}$ and Kamataki T: Ethnic differences between Japanese and Caucasians in the expression levels of mRNAs for CYP3A4, CYP3A5 and CYP3A7: lack of co-regulation of the expression of CYP3A in Japanese livers. Xenobiotica 35: 69-83, 2005.

31 Wang MY, Cheng JL, Han YH, Li YL, Dai JP and Shi DP: Measurement of tumor size in adult glioblastoma: classical cross-sectional criteria on 2D MRI or volumetric criteria on high resolution 3D MRI. Eur J Radiol 81: 2370-2374, 2012.

32 Takano T, Lin JH, Arcuino G, Gao Q, Yang J and Nedergaard M: Glutamate release promotes growth of malignant gliomas. Nat Med 7: 1010-1015, 2001.

33 Ishiuchi S, Tsuzuki K, Yoshida Y, Yamada N, Hagimura N, Okado H, Miwa A, Kurihara H, Nakazato Y, Tamura M, Sasaki $\mathrm{T}$ and Ozawa $\mathrm{S}$ : Blockage of $\mathrm{Ca}(2+)$-permeable AMPA receptors suppresses migration and induces apoptosis in human glioblastoma cells. Nat Med 8: 971-978, 2002.

34 Rösche J, Piek J, Hildebrandt G, Grossmann A, Kirschstein T and Benecke R: Perampanel in the treatment of a patient with glioblastoma multiforme without IDH1 mutation and without MGMT promotor methylation. Fortschr Neurol Psychiatr 83: 286-289, 2015.

35 Izquierdo1 C, Alentorn A, Idbaih A, Simó M, Kaloshi G, Ricard D, Barritault M, Meyronet D, Bruna J, Honnorat J, Delattre JY and Ducray F: Long-term impact of temozolomide on 1p/19qcodeleted low-grade glioma growth kinetics. J Neurooncol 136: 533-539, 2018.

36 Tensaouti F, Khalifa J, Lusque A, Plas B, Lotterie JA, Berry I, Laprie A, Cohen-Jonathan Moyal E and Lubrano V: Response Assessment in Neuro-Oncology criteria, contrast enhancement and perfusion MRI for assessing progression in glioblastoma. Neuroradiology 59: 1013-1020, 2017.

Received April 11, 2018

Revised June 5, 2018

Accepted June 6, 2018 